de Gruyter Lehrbuch

Pichler - Mathematische Systemtheorie 



\section{Mathematische Systemtheorie}

\section{Dynamische Konstruktionen}

von

Franz Pichler

Mit 29 Abbildungen

\begin{tabular}{|l}
$W$ \\
$\mathrm{DE}$ \\
$\mathrm{G}$
\end{tabular}

Walter de Gruyter · Berlin · New York 1975 


\section{Franz Pichler}

Ing., Dr. phil., o. Professor für Systemtheorie und Vorstand des Institutes für Statistik und Informatik an der Hochschule für Sozial- und Wirtschaftswissenschaften in Linz

(C) Copyright 1975 by Walter de Gruyter \& Co., vormals G. J. Göschen'sche Verlagshandlung, J. Guttentag, Verlagsbuchhandlung Georg Reimer, Karl J.Trübner, Veit \& Comp., Berlin 30.

Alle Rechte, insbesondere das Recht der Vervielfältigung und Verbreitung sowie der Übersetzung, vorbehalten. Kein Teil des Werkes darf in irgendeiner Form (durch Photokopie, Mikrofilm oder ein anderes Verfahren) ohne schriftliche Genehmigung des Verlages reproduziert oder unter Verwendung elektronischer Systeme verarbeitet, vervielfältigt oder verbreitet werden. Printed in Germany. Satz: Fotosatz Tutte, Salzweg-Passau. Druck: Grafik + Druck, München. Bindearbeiten: Lüderitz \& Bauer, Berlin.

Library of Congress Catalog Card Number: 74-79155

ISBN 3110039095 